\title{
The iscom structure as an immune-enhancing moiety: experience with viral systems
}

\author{
I. Claassen ${ }^{(1)(2)}$ and A. Osterhaus ${ }^{(1)}$ \\ (I) Laboratory of Immunobiology, and \\ (2) Laboratory of Control of Biological Products, National Institute of Public Health \\ and Environmental Protection, POB 1, 3720 BA Bilthoven (The Netherlands)
}

The iscom as an antigen-presenting structure

Extensive studies on fundamental mechanisms of protection induced by vaccination have led to insight into the components necessary for the induction of protective immunity. This has enabled vaccine researchers to focus on those components which are involved in the actual induction of immune responses and to exclude irrelevant, immunosuppressive or potentially harmful components from vaccines.

The "ideal" vaccine should meet the following requirements: the induction of a long-lasting antibody response of biologically active antibodies, which should be elicited even in the presence of maternal antibodies; functional T-cell responses which comprise both major histocompatibility complex (MHC) class-I- and class-II-restricted cytotoxic T cells (CTL) and helper $\mathrm{T}$ cells; long-lasting protection against infection with the pathogen. Furthermore, the production procedures must be suitable for large-scale production and the product must be stable during prolonged periods of storage and transport. Last but not least, it has to be safe and devoid of any undesirable side effects. New generations of vaccines will probably be composed of relevant antigen subunits either derived from the pathogen itself or prepared via molecular biological or synthetic techniques. However, vaccine formulations based on individual antigens or subunits bearing one or more B- and $T$-cell epitopes in a monomeric form have a major disadvantage: they are usually poorly immunogenic as compared to the original inactivated or attenuated pathogen. Therefore adjuvants or immune enhancers are needed to elicit the desired immune response. In general, adjuvants should contribute to the requirements stated above for the "ideal" vaccine. Most adjuvants however, only contribute to some of these, and concerns about undesirable side effects have largely prohibited their use in registered vaccines for humans.

In our laboratory, we have been especially in- terested in evaluating the potential of the immunestimulating complex (iscom) as a carrier for viral proteins.

Iscom was first described in 1984 (Morein et al., 1984). It is a cage-like structure, usually about 30 to $40 \mathrm{~nm}$ in diameter, composed of glycosides present in the adjuvant Quil-A, cholesterol, the immunizing (protein) antigen and also, in most cases, phospholipids. Although similar structures had been observed before (Horzinek et al., 1973), it was not until the work of Morein et al. that their potential as an immune-enhancing moiety was recognized.

Quil-A is a crude extract from the bark of Quillaja saponaria Molina which has potent adjuvant activity and is widely used as an adjuvant in veterinary vaccines. The adjuvant activity is due to the presence of a mixture of triterpine glycosides (Dalsgaard, 1978).

Although antigens of different origin including viruses, bacteria and parasites have been incorporated into iscoms (table I), in this review, we will mainly address data obtained with iscoms containing viral antigens. We will discuss the advantages and disadvantages of using Quil-A or iscoms as adjuvants. Furthermore, we will postulate a working hypothesis with respect to the mechanisms by which the iscom exerts its specific adjuvant activity.

The preparation procedure and structure of the iscom have been extensively described earlier (Höglund et al., 1989). Recent studies have generated detailed information on the structure of the iscom. The typical cage-like structure is formed by Quil$\mathrm{A} /$ cholesterol micelles which are held together by hydrophobic forces (Özel et al., 1989). This structure is very stable. Iscoms can resist repeated freezethawing and the structure remains intact upon lyophilization. The minimal requirements for the formation of iscoms have been extensively described (Lövgren and Morein, 1988). Quil A is a necessary constituent of the iscom structure. The size and mor- 


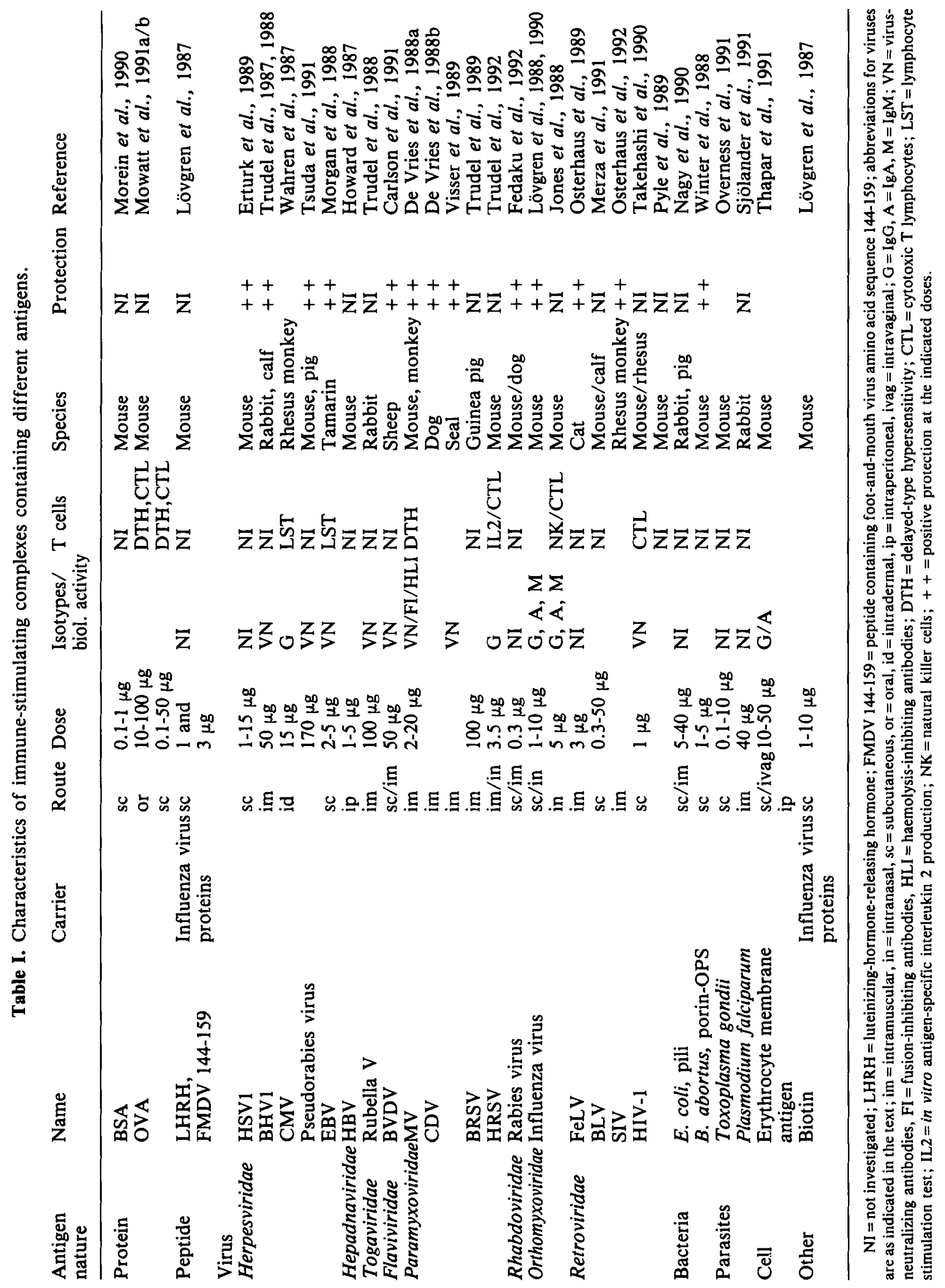


Table II. A schematic outline representing the procedures leading to iscom production.

1. Solubilization of (membrane) proteins by adding detergent e.g. TX-100, MEGA-10, octylglucoside.

2. Separation of solubilized and non-solubilized proteins.

3. Addition of Quil-A, cholesterol and phospholipid.

4a. Removal of detergent by dialysis.

4b. Removal of detergent by centrifugation on a Quil-A-containing sucrose gradient.

5. Removal of free Quil-A by centrifugation through a $10 \%$ sucrose cushion.

6. Analysis of iscom formation and quality by: negative contrast electron microscopy, SDS-PAGE, immunoblotting and antigen-specific ELISA.

phology of an iscom is independent of the protein incorporated. In fact, "empty" iscoms can be made which solely contain Quil A and cholesterol. This cholesterol iscom or iscom matrix is a very rigid and uniform structure. The incorporation of amphipatic oligo- or polypeptides requires the addition of phospholipids like phosphatidyl ethanolamine or phosphatidyl choline. It is speculated that the incorporation of phospholipids provides the flexibility necessary for the incorporation of proteins in the structure (Lövgren and Morein, 1988).

Table II represents a schematic outline of the principles used for the formation of iscoms. They are formed spontaneously when detergent is removed in a controlled fashion from a mixture of cholesterol, protein, phospholipid, detergent and Quil-A. Detergents are generally needed to obtain and keep (membrane) proteins in a monomeric form. The best results with many viral membrane proteins were obtained when octylglucoside or MEGA-10 (decanoyl-Nmethylglucamide) were used as detergents. The detergent can be removed in several ways, but dialysis and centrifugation on a Quil-A-containing sucrose gradient have been used most frequently. The centrifugation method may be used when a nondialysable detergent like Triton-X100 is used. Iscom formation is confirmed by negative contrast electron microscopy (fig. 1). Furthermore, iscoms have a well defined sedimentation (19 S) constant in a sucrose gradient.

One of the interesting features of iscom technology is the fact that a wide range of proteins can be incorporated in the structure. Most viral membrane proteins are spontaneously incorporated upon formation of the iscom structure. For the introduction of proteins which do not possess membrane insertion sequences several methods have been developed. Pretreatment of hydrophilic proteins, e.g. BSA, by adjustment at low $\mathrm{pH}(2.5)$, reveals hydrophobic

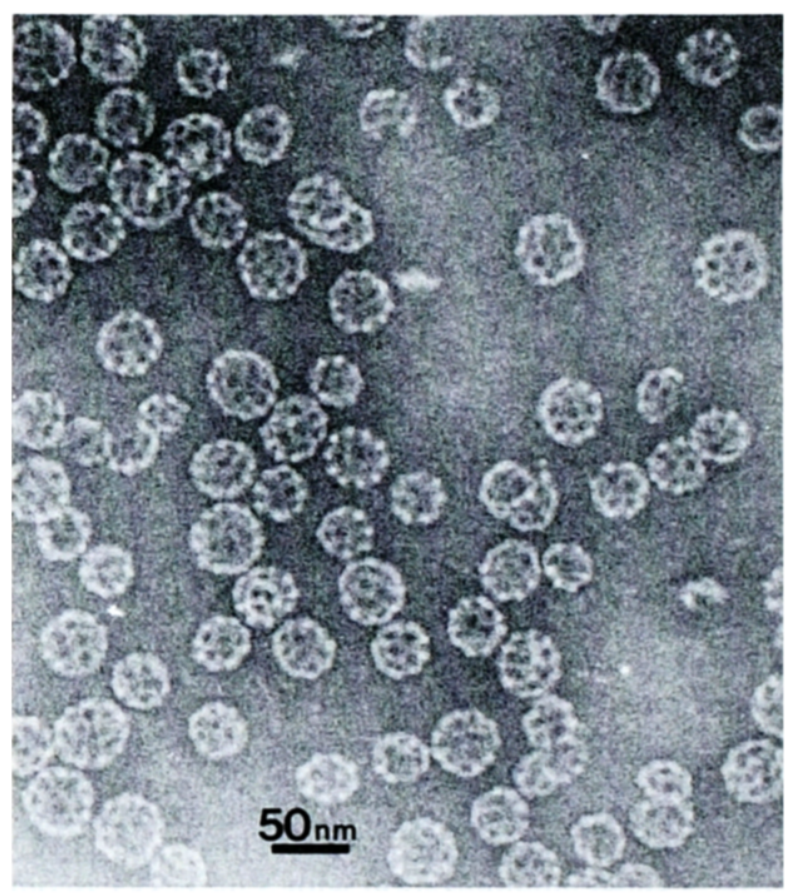

Fig. 1. Electron micrograph $\times 140,000$ after negative contrast staining of iscoms which contain measles virus antigens showing the typical cage-like structure.

regions normally hidden inside the protein structure and allows these regions to interact with the iscom matrix (Morein et al., 1990). Palmitification of proteins, the coupling by overnight incubation with palmitoyloxy-succinimide, prior to iscom formation, is also used to enable the incorporation of nonmembrane proteins. The immune response against ovalbumin iscoms prepared in this way proved to be 
as expected for iscoms (Mowat et al., 1991a). The acid treatment may be harmful especially to certain conformation-dependent epitopes. The water-soluble nucleoprotein (NP) of influenza virus was chemically linked to bacterial lipopolysaccharide which enabled its subsequent incorporation in the iscom structure (Weiss et al., 1990).

So far only limited data are available on the incorporation of peptides into iscom and the immunogenicity of such iscoms, although many studies are presently being carried out in this area (K. Lövgren, personal communication). It was shown that the response against a peptide based on the foot-andmouth disease virus amino acid sequence which was coupled to preformed influenza virus iscoms did not induce very high anti-peptide antibody titres (Lövgren et al., 1987). Using recombinant DNA techniques, a Plasmodium falciparum antigen sequence was produced as a fusion protein in Escherichia coli. When coupled to influenza virus iscoms, this antigen was shown to be immunogenic in rabbits (Sjölander et al., 1991).

\section{Protective immune responses against viruses induced by iscoms}

\section{Herpesviridae}

Viruses which belong to the Herpesviridae family are important pathogens which can establish acute and latent infections in many animal species including man. Both humoral and cellular immunity are considered important for protection against infection with these viruses. Herpes simplex virus 1 (HSV1) and 2 (HSV2) are members of the Alphaherpesvirinae subfamily which infect man. Iscoms have been prepared with membrane proteins of these viruses and tested for their immunogenicity and protective potential. Mice generated significant antibody titres after immunization with HSV1 iscoms and were protected against a lethal challenge with HSV1 and HSV2 after a single immunization with $5 \mu \mathrm{g} \mathrm{HSV1}$ iscom (Erturk et al., 1989).

Pseudorabies virus (PrV), another member of the Alphaherpesvirinae subfamily, causes disease and death in piglets. The selective incorporation of viral protcins in iscoms could be useful to discriminate between vaccinated and non-vaccinated animals with subclinical infection. Iscoms containing the gII glycoprotein of $\mathrm{PrV}$ induced complement-dependent virus-neutralizing antibodies in mice (Tsuda et al., 1991). A 1- $\mu \mathrm{g}$ dose provided partial protection in mice. Pigs immunized with $170 \mu \mathrm{g}$ gII iscoms were completely protected against lethal challenge.

Bovine herpes virus type I (BHV1), yet another member of this subfamily, is an important pathogen in cattle which causes infectious rhinotracheitis and maybe responsible for other clinical manifestations. Differentiation between vaccinated and infected cattle on the basis of serology is possible when subunit vaccines are used that selectively incorporate certain proteins. Iscoms containing the envelope glycoproteins of BHV1 were shown to be immunogenic in rabbits (Trudel et al., 1987) and calves (Trudel et al., 1988a; Merza et al., 1991a). Both species developed virus-neutralizing and haemagglutination-inhibiting antibodies. Calves vaccinated with either 50 or $100 \mu \mathrm{g}$ BHV1 iscoms were protected against challenge with $5 \times 10^{6}$ $\mathrm{TCID}_{50}$ BHV1. A control group of animals which had received a commercial inactivated vaccine proved to be unprotected against viraemia in the same experiment (Merza et al., 1991b).

Infection with cytomegaloviruses (CMV), which belong to the subfamily Betaherpesvirinae, results in the establishment of latent infections in many species that may eventually lead to serious complications in immunocompromized hosts. Monkeys which were immunized with either CMV-infected monocytes or CMV iscoms developed anti-CMV antibody titres (Wahren et al., 1987). Cellular responses, measured in lymphocyte stimulation tests (LST), were of similar magnitude in both groups. Less antigen $(15 \mu \mathrm{g})$ was needed when CMV iscoms were administered intradermally. However, $150 \mu \mathrm{g}$ of free unadjuvanted CMV nucleocapsid invoked poor cellular responses. No protection studies were carried out in this study.

Epstein Barr virus (EBV), belonging to the subfamily Gammaherpesvirinae, infects man and is the causative agent of infectious mononucleosis in industrialized countries. In certain developing countries it is associated with the development of undifferentiated nasopharyngeal carcinoma and Burkitt's lymphoma. Cottontop tamarin monkeys (Saguinus oedipus) develop tumours after infection with a high dose of EBV. Iscoms containing the EBV glycoprotein gp 340 induced virus-neutralizing antibodies. A $5-\mu \mathrm{g}$ dose of gp340 iscoms given 3 times protected the monkeys completely from tumour development (Morgan et al., 1988). Human T cells from EBV-seropositive donors could be stimulated in vitro with gp340 iscoms (Ulaeto et al., 1988).

\section{Hepatitis B virus}

Hepatitis B virus (HBV), a member of the Hepadnaviridae family, causes a chronic infection in man which may eventually lead to the development of primary liver cancer. The first generation vaccines consisted of hepatitis B surface antigen (HBsAg) particles $(20 \mathrm{~nm})$ purified from plasma of infected donors. Recombinant DNA techniques have made it possible to produce $\mathrm{HBsAg}$ particles in yeast cells (McAleer et al., 1984). Alum was required as an ad- 
juvant to enhance immunogenicity of these particles. Immunization of mice with iscoms containing $\mathrm{HBsAg}$ derived from yeast generated high levels of HBVspecific antibodies (Howard et al., 1987).

\section{Rubella virus}

Infection with rubella virus, a member of the family Togaviridae, may cause a mild morbilliform rash, occasional fever, and a rather predictable lymphadenopathy in man. Since infection during pregnancy leads to neonatal malformations, vaccination during childhood is widely practiced. A live attenuated rubella virus is used for vaccination worldwide. Iscoms containing the E1 glycoprotein (haemagglutinin) and the nucleoprotein of rubella virus have been prepared. Humoral immune responses in rabbits were as high as those observed with a commercial live-virus vaccine. The presence of virus-neutralizing and haemagglutination-inhibiting antibodies was demonstrated. Small amounts of the viral nucleoprotein were present in these iscoms which may be beneficial for the development of cellular immunity (Trudel et al., 1989b).

\section{Bovine virus diarrhoea virus (BVDV)}

BVDV a member of the Flaviviridae family, usually causes subclinical infections in sheep and cattle. Vertical transmission of the virus may lead to abortion and teratogenic defects. Lectin affinitypurified BVDV proteins were incorporated in iscoms. Pregnant sheep were given two 50- $\mu$ g doses of BVDV iscoms. All animals developed anti-BVDV antibodies with neutralizing activity. Significant protection was observed against a challenge of the sheep with BVDV. Some 26 lambs out of 29 were born in the vaccinated group whereas only 5 lambs out of 26 foetuses were born in the non-vaccinated animals (Carlsson et al., 1991).

\section{Paramyxoviridae}

The potential of iscoms for the development of subunit vaccines against members of the genus morbillivirus has been explored in our laboratory. Whole measles virus iscoms, which contain the fusion protein $(F)$ and minor amounts of the haemagglutinin protein $(\mathrm{H})$, induced virus-neutralizing, haemagglutination-inhibiting and fusion-inhibiting antibodies. Iscoms containing immuno-affinity-purified $\mathrm{F}$ (F-iscom) induced antibodies with haemolysis inhibition (HLI) activity but devoid of VN activity. Both $\mathrm{F}$ and $\mathrm{H}$ iscom preparations induced protection against intracerebral challenge with a rodent-adapted measles virus strain (De Vries et al., 1988a; Varsanyi et al., 1987). Immunization with F-iscom induced a measles-virus-specific cellular response, delayed type hypersensitivity (DTH) and measles-virus-specific $\mathrm{T}$-cell clones could be generated from these mice (De Vries et al., 1988a). MV iscom also induced humoral (in monkey) and cellular (in mice) immune responses in the presence of passively transferred antibodies, a situation that mimics vaccination in the presence of maternal antibodies (De Vries et al., 1990).

Canine distemper virus (CDV) is a morbillivirus closely related to measles virus that causes a disease in dogs with a pathogenesis similar to measles in man. CDV iscoms were shown to protect dogs against viraemia and clinical signs upon intranasal challenge with a virulent strain of the virus (De Vries et al., 1988b).

CDV iscoms were also used to vaccinate seals against phocoid distemper virus (PDV), a recently discovered morbillivirus that caused mass mortality among seals in the North Sea in 1988 (Osterhaus et al., 1989b; Visser et al., 1989). Vaccination was successful since all animals developed PDV-neutralizing antibodies. Upon challenge with PDV, vaccinated animals were protected whereas two sham-vaccinated animals developed clinical signs and died.

Respiratory syncytial virus (RSV) is another Paramyxovirus which causes severe lower respiratory tract infections in man and cows. Guinea pigs immunized with iscoms based on human or bovine RSV developed cross-neutralizing antibody titres. In mice, intramuscular immunization with RSV-iscoms induced virus-neutralizing antibodies, CTL activity and protection against virus challenge (Trudel et al., 1989; Trudel et al., 1992).

\section{Rabies virus}

Rabies virus belongs to the Rhabdoviridae family and causes fatal disease in warmblooded animals. Most currently used vaccines against rabies virus are inactivated viruses which are used for pre- and postexposure treatment of rabies infection. Rabies virus iscoms prepared from whole purified virus were among the first iscoms described (Morein et al., 1984). In vitro experiments showed that human $\mathrm{CD}^{+}{ }^{+} \mathrm{T}$-cell clones could be stimulated with these iscoms. Moreover, in vitro stimulation of human peripheral blood lymphocytes with rabies virus iscoms led to the production of virus-neutralizing antibodies. Immunization of mice with rabies virus iscoms induces a DTH response and neutralizing antibody titres (Höglund et al., 1989). In our laboratory, we have generated data which show that both MHC class-I- and class-II-restricted T-cell responses can be generated after immunization of mice with rabies virus (Claassen et al., submitted). Iscoms which contain lentil-lectin-purified rabies virus glycoprotein 
were shown to be immunogenic in both mice and dogs. These iscoms could protect dogs against a lethal challenge with street rabies virus after pre-exposure immunization. Moreover post-exposure protection against street rabies virus challenge could be induced with three 120-ng doses of rabies virus glycoprotein iscom in $90 \%$ of mice but not with three doses of a widely used human diploid cell vaccine (HDCV). When mice were given four doses of HDCV for postexposure treatment they died of anaphylactic shock. No such phenomenon was observed when the mice had been immunized with the iscom preparation (Fedaku et al., 1992).

\section{Influenza virus}

Influenza viruses (family Orthomyxoviridae) primarily infect the respiratory tract of many animal species. Therefore, local immune responses in the lung are considered important for protection. The two membrane proteins important for eliciting protective immune responses are haemagglutinin (HA) and neuraminidase (NA). The HA molecule is subject to antigenic drift which interferes with the protection elicited by vaccines based on the relevant strains. Cross-reactive cellular immune responses rapidly reduce virus titres in the lung and are therefore considered important.

Intranasal immunization of mice with two doses of 5- $\mu$ g HANA iscoms elicited antibody titres (IgM, IgG and IgA) comparable to those elicited by virus infection (Jones et al., 1988 and Lövgren, 1988). Furthermore, virus-specific antibody-secreting cells could be demonstrated in the lungs. In contrast, the same dose of HANA micelles induced lower responses of mainly IgM antibodies and no local B-cell memory. Serum antibody responses could also be demonstrated in guinea pigs and horses (Sundquist et al., 1988). Both iscoms and micelles induced CTL precursors in the lungs of mice but the levels were four-fold higher in iscom-immunized mice. Natural killer cells were found in similar quantities after immunization with either of the antigen preparations (Jones et al., 1988). Complete protection of mice against intranasal challenge with influenza virus could be induced by intranasal and subcutaneous immunizations with HANA iscoms (Sundquist et al., 1988 and Lövgren et al., 1990). Iscoms containing the influenza nucleoprotein induced virus-specific antibody titres but no specific CTL responses were observed. About $50 \%$ of the immunized mice survived challenge with a virulent mouse-adapted strain (Weiss et al., 1990).

\section{Retroviridae}

Iscoms containing the gp70/85 envelope protein of feline leukaemia virus (FeLV), a type $C$ virus of the Retroviridae family, can induce protection in cats. Antibody responses as determined by ELISA, immunofluorescence, virus neutralization and Western blotting showed that over $80 \%$ of iscom-immunized cats responded compared to only $6 \%$ of a group of cats vaccinated with a commercial vaccine (Akerblom et al., 1989; Osterhaus et al., 1985 and 1989a).

Iscoms containing gp51 of bovine leukaemia virus (BLV, HTLV/BLV group) induced good humoral immune responses in mice and calves (Merza et al., 1991a). In calves, neutralizing antibodies could be measured after the second inoculation. These results showed the potential of iscoms for retrovirus vaccine development.

Human immunodeficiency virus type 1 (HIV1) (subfamily Lentivirinae) is the causative agent of AIDS in man. Until now, no safe and effective vaccines against this disease are available. The development of a suitable vaccine is hampered by the variability of the viral envelope protein gp 120 which induces neutralizing antibodies. Multiple injections in rhesus monkeys with iscoms containing gp120 of HIV1 induced ten-fold higher neutralizing titres than comparable amounts of gp120 with an alum adjuvant (Pyle et al., 1989). In mice, a 5- $\mu \mathrm{g}$ dose of these gp120 iscoms induced two-fold higher titres when compared with a $50-\mu \mathrm{g}$ dose of gp120 in complete Freunds' adjuvant. Sera from rhesus monkeys (Macaca mulatta) cross-neutralized RF and MN isolates of HIV. The induction of class-I-restricted precursor CTL in mice was demonstrated using gp 160-iscom-immunized mice. Spleen cells obtained from these mice could kill target cells expressing HIV gpl60 or pulsed with a known immunodominant CTL peptide (Takahashi et al., 1990).

Several animal models exist to study the immunity and pathogenesis of HIV-related viruses. Simian immunodeficiency virus (SIV) is a closely related lentivirus which can infect rhesus macaques and cause an AIDS-like syndrome. In a recent study from our laboratory, it was demonstrated that a SIV-iscom preparation as well as whole inactivated SIV adjuvanted with muramyl dipeptide (MDP) could protect animals against an intravenous homologous challenge with $10 \mathrm{MID}_{50}$ of cell-free SIV. All animals were protected from developing SIV-specific viraemia for at least a twelve-week period after challenge. Fifty percent of the vaccinated animals in a similar experiment were also protected for at least nine weeks against an intravenous challenge with SIV-infected peripheral blood mononuclear lymphocytes (Osterhaus et al., 1992). In another study, cynomolgus monkeys (Macaca fascicularis) were infected with HIV2 after immunization with HIV2-iscoms or inactivated HIV2 with complete Freund's adjuvant (CFA) (Putkonen et al., 1991) HIV2-iscom-immunized monkeys were not protected against infection with HIV2 which was probably 
due to the virtual absence of $\mathrm{gp} 125$ in the iscom preparation used. These results demonstrate that vaccination against lentivirus infections should not be considered impossible.

\section{General considerations for the use of iscoms as an antigen-presenting moiety}

\section{Mode of administration}

Iscom preparations have generally been administered intramuscularly or subcutaneously. Only small amounts -1 to $10 \mu \mathrm{g}$ - of incorporated antigens are needed to elicit effective immune responses in mice. It was found that the time between first and second immunization is critical for the development of a booster response. An interval between 6 to 8 weeks seems optimal to elicit a booster effect (Lövgren et al., 1990). Short immunization protocols like the NIH efficacy test for rabies vaccines, in which case the interval is only one week, give lower titres and protection levels. One intraperitoneal immunization of mice with $360 \mathrm{ng}$ of rabies virus glycoprotein iscom is sufficient to protect almost $90 \%$ against intracerebral challenge with rabies virus (Fedaku et al., 1992).

Recently the use of iscoms for oral immunization was also investigated. Attempts to investigate the possibility of oral immunization were undertaken with influenza virus iscoms but these were largely unsuccessful, probably because the administered antigen dose was too low, i.e. $5 \mu \mathrm{g}$ (Lövgren, 1988). No systemic antibody response could be measured and it was speculated that iscoms could not resist degradation in the gastrointestinal tract. Intranasal immunization with influenza virus iscoms, however, led to a specific antibody response of all classes and subclasses, including IgA, and also to cellular responses in the lung (Jones et al., 1988). This showed that local immunization with iscoms may lead to the induction of both local and systemic immune responses. Ovalbumin(OVA)-containing iscoms were shown to be immunogenic after systemic but also after oral immunization (Mowat et al., 1991). Oral immunization with OVA iscom induced specific serum antibodies. Cellular responses were measured by DTH response. The required dose for oral immunization was 10 times higher $(100 \mu \mathrm{g})$ than that needed for parenteral immunization, which is probably due to partial degradation of the immunogen in the gastrointestinal tract before iscoms can reach immunocompetent cells or lymphoid organs in the gut. Repeated feeding with OVA-iscom induced MHC class-I-restricted CTL specific for OVA (Mowat et al., 1991). When soluble OVA was given orally in comparable amounts no responses could be measured.
Secretory immune responses in the vagina of mice could be measured after intraperitoneal, subcutaneous or intravaginal immunization with iscom containing sheep red blood cell (SRBC) membrane antigens. Non-mucosal immunization in the pelvis induced higher systemic and local titres than local application, and local application required 10 times higher amounts of antigen (Thapar et al., 1991).

The finding that iscom can be used for local immunization is important for the development of protection against pathogens which acquire access through mucosal membranes and therefore require musocal immunity. The importance of the mucosal immune system for vaccine development has recently been reviewed (McGhee et al., 1992).

\section{Toxicological aspects}

When iscoms are considered as vaccine candidates for humans, toxicological aspects of the incorporated adjuvant Quil-A should be considered. So far, one study has been published on the in vivo effects of Quil-A-containing iscoms after intramuscular injection (Speijers et al., 1988). Only a moderate inflammatory reaction was observed in 1 out of 6 rats which had received an iscom dose containing $60 \mu \mathrm{g}$ Quil-A. It should be noted that the haemolytic activity of Quil-A incorporated in iscom is ten times lower than observed with free Quil-A (Kersten, 1991).

Attempts have been made to separate the individual components of Quil-A in order to segregate the haemolytic and adjuvant activity (Kensil et al., 1991 ; Kersten, 1991). Kensil described the separation by reverse-phase HPLC of Quil-A into 4 fractions which all retained their adjuvant activity. One fraction (QS-7) showed no direct lethal effect in mice at a dose of $500 \mu \mathrm{g}$. Unfortunately this fraction was not tested for its ability to form iscoms. Kersten, using the same approach, reported the separation of Quil-A into 23 fractions. Six of these purified saponins could be used to form iscom-like particles of varying size, but these were consistently larger than iscoms prepared from unpurified Quil-A. Immunogenicity studies were performed using iscom with the gonococcal PI protein incorporated. Iscoms made with the so-called fraction QA-3 were as immunogenic as total Quil-A iscoms. The haemolytic activity of QA-3 was 15 times reduced as compared to total Quil-A. Since the mean size of QA-3-iscoms is between 110 and $145 \mathrm{~nm}$, the influence of particle size on immunogenicity has to be evaluated.

It should be noted that no negative side effects have been observed with the use of an iscom-based commercial equine influenza vaccines in horses (Sundquist et al., 1988), or with any other iscom preparation (Nagy et al., 1990). Moreover, Quil-A is accepted in veterinary vaccine preparations for pigs 
and cows at 10 to 100 milligram doses, about 100 to 1,000 -fold higher than that used in iscom preparations. Nevertheless, before iscom can be used in vaccines for human application, further toxicological studies are needed. These studies should focus on iscoms and their individual components and should deal with acute and subacute toxicity as well as possible mutagenic effects and sensitization. This may be omitted for iscom administered orally since saponins are accepted food additives.

\section{How do iscoms work?}

The quantitative and qualitative effects on the immune responses as found after iscom immunization raise the question as to what determines the immunogenicity of the iscom structure. The higher and, in some cases, longer persisting antibody titres can easily be explained if one assumes that incorporated Quil-A retains its normal adjuvant activity. It has been suggested that the retention time of the immunizing antigen at the injection site and the uptake amount in the lymphoid organs, as observed with influenza iscoms (Watson et al., 1989) and with Quil-A as adjuvant (Scott et al., 1985) may be important for the observed effects. However, when Quil-A was used as adjuvant, the inflammatory reaction and antigen retention could be completely inhibited by the addition of cholesterol without affecting adjuvant activity (Scott et al., 1985). A progressive redistribution of iscom-bound radioactive labelled antigen to the spleen was observed when compared to antigen in micelles (Watson et al., 1989). Furthermore, we have recently observed that iscoms in vivo are taken up in mice by a distinct subset of macrophages in the spleen which is not involved in the uptake of free inactivated antigen (Claassen et al., submitted).

Furthermore, the multimeric presentation form of the incorporated proteins and the presence of Quil-A in the same unique structure proved to be essential for the observed effects. Using different biotin/protein ratios, it was shown that at least 3 biotin molecules have to be coupled to a preformed iscom to induce an antibody response 10 times higher than that achieved when only one biotin molecule is coupled (Lövgren et al., 1987). This finding clearly illustrates that the multimeric form is important for the observed adjuvant activity of the iscom structure. Although speculative, this might also be necessary for the induction of MHC class-I-restricted CTL, even when proteins like OVA, which are normally not immunogenic for these $T$ cells are included. It is generally accepted that at least two distinct routes exist for the degradation of foreign antigen and the presentation different subsets of $\mathrm{T}$ cells (Yewdell and Bennink, 1990). First, the uptake of antigens into lysosomes, which leads to the degradation of foreign proteins and to the formation of peptides which then associate with MHC class II molecules and are recognized by $T$ cells bearing the CD4 marker. Secondly, the cytosolic processing pathway into which enter proteins which are synthesized in the cytosol, released into the cytosol by lysis of endosomes or by antigens penetrating through the plasma or endosomal membranes. This pathway generates peptides that associate with MHC class I molecules which are recognized by $\mathrm{CD} 8^{+} \mathrm{T}$ cells. In general, non-replicating antigens do not enter the cytosolic pathway, so that no priming for MHC class-I-restricted CTL occurs. The ability of iscoms to stimulate CD8 ${ }^{+} \mathrm{CTL}$ in vivo has been demonstrated with different iscom preparations (Jones et al., 1988; Takahashi et al., 1990; Mowat et al., 1991; Trudel et al., 1992), even after oral immunization (Mowat and Donachi, 1991). In our laboratory, data have been generated which show that iscoms can stimulate MHC class-I-specific CTL in vitro (van Binnendijk et al., submitted) and in vivo (Claassen et al., submitted). The in vitro stimulation of measles-virus-specific CTL is dependent on the presence of MHC class-I-matched antigen-presenting cells. It may thus be hypothesized that at least in vitro iscoms are able to enter the cytosolic processing pathway which leads to expression of peptides in the context of MHC class I molecules. Iscoms could act as a carrier enabling proteins to penetrate the plasma and endosomal membranes partially or entirely, thus exposing iscom-bound protein to both proteolytic compartments. Perhaps iscoms are not only taken up by APC to enter the lysosomal compartment but they may also pass through or into the membrane of the cells, meanwhile protecting the protein for proteolytic degradation, and thus exposing the protein to cytoplasmic proteases. Intact and partially degraded iscoms could be demonstrated attached to macrophage cell membranes and within phagosomal membranes in close association with phagosomal membranes but not in the cytoplasm (Watson et al., 1989).

The proposed capability of iscom to pass into the membrane may be explained by their hydrophobic structure, and because they contain saponins which can intercalate into cholesterol membranes (Özel et al., 1989). This in fact determines the haemolytic properties of Quil-A. Iscoms are extremely stable structures and thus may be able to pass through cell or lysosomal membranes and so enter the cytosolic processing pathway thereby stimulating $\mathrm{CD8}^{+} \mathrm{CTL}$.

\section{Conclusion}

In summary, we conclude that the iscom matrix is a promising moiety for the presentation of antigen to the immune system. It lacks many of the disadvantages of traditional live vaccines as regards 
safety. The major points in favour of an iscom approach to developing new vaccines are the following: they generate long-lasting biologically functional antibody responses; they generate immunological responses in the presence of maternal antibodies; they generate functional cell-mediated immune responses; they generate protection in several systems. However, before iscom technology can be applied to the production of vaccines for human use the toxicity of individual iscom preparations will have to be studied and documented in more detail. Since there is an urgent need for new generations of vaccines, especially against viral infections like HIVI, EBV and RSV, the further development of the iscom as an immune-enhancing moiety deserves more attention.

\section{Acknowledgements}

The authors would like to acknowledge J.S. Teppema for electron microscopy and Prof. B. Morein for helpful discussions.

\section{References}

Åkerblom, L., Strömstedt, K., Höglund, S., Osterhaus, A.D.M.E. \& Morein, B. (1989), Formation and characterization of FeLV iscoms. Vaccine, 7, 142-146.

Carlson, U., Alenius, S. \& Sundquist, B. (1991), Protective effect of an iscom bovine virus diarrhoea virus (BVDV) vaccine against an experimental BVDV infection in vaccinated and non-vaccinated pregnant ewes. Vaccine, 9, 577-580.

Dalsgaard, K. (1978), A study of the isolation and characterization of the saponin Quil A. Evaluation of its adjuvant activity with special reference to the application in the vaccination of cattle against foot-and-mouth disease. Acta. Vet. Scand. (suppl.), 69, 1-40.

De Vries, P., Binnendijk, R.S., Van der Marel, P., Van Wezel, A.L., Voorma, H.O., Sundquist, B., UytdeHaag, F.G.C.M. \& Osterhaus, A.D.M.E. (1988a), Measles virus fusion protein presented in an immunestimulating complex (iscom) induces haemolysisinhibiting and fusion-inhibiting antibodies, virusspecific T cells and protection in mice. J. gen. Virol., 69, 549-559.

De Vries, P., UytdeHaag, F.G.C.M. \& Osterhaus, A.D.M.E. (1988b), Canine distemper virus (CDV) immune-stimulating complexes (iscoms), but not measles virus iscoms, protect dogs against CDV infection. J. gen. Virol., 69, 2071-2083.

De Vries, P., Visser, I.K.G., Groen, J., Broeders, H.W.J., UytdeHaag, F.G.C.M. \& Osterhaus, A.D.M.E. (1990), Immunogenicity of measles virus iscoms in the presence of passively transferred MV-specific antibodies, in "Vaccines 90: Proceedings of the meeting "Modern Approaches to New Vaccines Including the Prevention of AIDS" 20-24 september 1989" (pp. 139-144). Cold Spring Harbor Laboratory, New York.

Ertürk, M., Jennings, R., Hockley, D. \& Potter, C.W.
(1989), Antibody responses and protection in mice immunized with herpes simplex virus type I antigen immune-stimulating complex preparations. J. gen. Virol., 70, 2149-2155.

Fekadu, M., Shaddock, J.H., Ekstrom, J., Osterhaus, A., Sanderlin, D.W., Sundquist, B. \& Morein, B. (1992), An immune-stimulating complex subunit rabies vaccine protects mice and dogs against street rabies challenge. Vaccine, 10, 192-197.

Höglund, S., Dalsgaard, K., Lövgren, K., Sundquist, B., Osterhaus, A. \& Morein, B. (1989), Iscoms and immunostimulation with viral antigens, in "Subcell. Biochem." (J.R. Harris), 15 (pp. 39-68). Plenum Press, New York.

Horzinek, M.C. (1973), The structure of togaviruses. Progr. med. Virol., 16, 109-156.

Howard, C.R., Sundquist, B., Allan, J., Brown, S.E., Chen, S.H. \& Morein, B. (1987), Preparation and properties of immune-stimulating complexes containing hepatitis B virus surface antigen. J. gen. Virol., 68, 2281-2289.

Jones, P.D., Tha Hla, R., Morein, B., Lövgren, K. \& Ada, G.L. (1988), Cellular immune responses in the murine lung to local immunization with influenza $\mathrm{A}$ virus glycoproteins in micelles and immunostimulatory complexes (iscoms). Scand. J. Immunol., 27, 645-652.

Kensil, C.R., Patel, U., Lennick, M. \& Marciani, D. (1991), Separation and characterization of saponins with adjuvant activity from Quillaja saponaria molina cortex. J. Immunol., 146, 431-437.

Kersten, G.F.A. (1991), Aspects of iscoms. Analytical, pharmaceutical and adjuvant properties. Thesis, State University, Utrecht.

Lövgren, K., Lindmark, J., Pipkorn, R. \& Morein, B. (1987), Antigenic presentation of small molecules and peptides conjugated to a preformed iscomas carrier. J. Immunol. Methods, 98, 137-143.

Lövgren, K. (1988), The serum antibody response distributed in subclasses and isotypes after intranasal and subcutaneous immunization with influenza virus immunostimulating complexes. Scand. J. Immunol., $27,241-245$.

Lövgren, K. \& Morein, B. (1988), The requirement of lipids for the formation of immunostimulating complexes (iscoms). Biotechn. appl. Biochem., 10, 161-172.

Lövgren, K., Kaberg, H. \& Morein, B. (1990), An experimental subunit vaccine (iscom) induced protective immunity to influenza virus infection in mice after a single intranasal administration. Clin. exp. Immunol., 82, 435-439.

Merza, M., Sober, J., Sundquist, B., Toots, I. \& Morein, B. (1991a), Characterization of purified gp51 from bovine leukemia virus integrated into iscom. Physicochemical properties and serum antibody response to the integrated gp51. Arch. Virol., 120, 219-231.

Merza, M., Tibor, S., Kucsera, L., Bognar, G. \& Morein, B. (1991b), Iscom of BHV-1 envelope glycoproteins protected calves against both disease and infection. J. Vet. Med., 38, 306-314.

McAleer, W.J., Buynak, E.B., Maigetler, R.Z., Wampler, D.E., Miller, W.J. \& Hilleman, M.R. (1984), Human hepatitis B vaccine from recombinant yeast-derived surface antigen. Nature (Lond.), 307, 178-180.

McGhee, J.R., Mestecky, J., Dertzbaugh, M.T., Eldridge, J.H., Hirasawa, M. \& Kiyono, H. (1992), The 
mucosal immune system : from fundamental concepts to vaccine development. Vaccine, $10,75-88$.

Morein, B., Sundquist, B., Höglund, S., Dalsgaard, K. \& Osterhaus, A.D.M.E. (1984), Iscom, a novel structure for antigenic presentation of membrane proteins from enveloped viruses. Nature (Lond.), 308, 457-459.

Morein, B., Ekström, J. \& Lövgren, K. (1990), Increased immunogenicity of a non-amphipatic protein (BSA) after inclusion into iscoms. J. Immunol. Methods, $128,177-181$.

Morgan, A.J., Finerty, S., Lövgren, K., Scullion, F.T. \& Morein, B. (1988), Prevention of Epstein-Barr (EB) virus-induced lymphoma in cottontop tamarins by vaccination with the EB virus envelope glycoprotein gp340 incorporated into immune-stimulating complexes. J. gen. Virol., 69, 2093-2096.

Mowat, A.M., Donachie, A.M., Reid, G. \& Jarrett, O. (1991), . Immune-stimulating complexes containing Quil A and protein antigen prime class $1 \mathrm{MHC}$ restricted $T$ lymphocytes in vivo and are immunogenic by the oral route. Immunology, 72, 317-322.

Mowat, A.M. \& Donachie, A.M. (1991), Iscoms - a novel strategy for mucosal immunization? Immunol. Today, 12, 383-385.

Nagy, B., Höglund, S. \& Morein, B. (1990), Iscom (immunostimulating complexes) vaccines containing mono- or polyvalent pili of enterotoxigenic $E$. coli; immune response of rabbit and swine. J. Vet. Med., 37, 728-738.

Överness, G., Nesse, N.N., Waldeland, Lövgren, K. \& Gudding, R. (1991), Immune response after immunization with an experimental Toxoplasma gondii iscom. Vaccine, 9, 25-28.

Osterhaus, A.D.M.E., Weijer, K., UytdeHaag, F.G.C.M., Jarrett, O., Sundquist, B. \& Morein, B. (1985), Induction of protective immune response in cats by vaccination with feline leukemia virus iscoms. J. Immunol., 135, 591-596.

Osterhaus, A., Weijer, K., UytdeHaag, F., Knell, P., Jarrett, O. \& Morein, B. (1989a), Serological responses in cats vaccinated with FeLV-iscom and an inactivated FeLV vaccine. Vaccine, 7, 137-141.

Osterhaus, A.D.M.E., UytdeHaag, F.G.C.M., Visser, I.K.G., Vedder, E.J., Reijnders, P.J.M., Kuiper, J. \& Brugge, H.N. (1989b), Seal vaccination success. Nature (Lond.), 337, 21.

Osterhaus, A.D.M.E., de Vries, P. \& Heeney, J. (1992), AIDS vaccine developments. Nature (Lond.), 355 , 684-685.

Özel, M., Höglund, S., Gelderblom, H.R. \& Morein, B. (1989), Quaternary structure of the immunostimulating complex (iscom). J. Ultrastruct. mol. Struct. Res., 102, 240-248.

Putkonen, P., Thorstensson, R., Walther, L., Albert, J., Åkerblom, L., Granquist, O., Wadell, G., Norrby, E. \& Biberfeld, G. (1991), Vaccine protection against HIV-2 infection in cynomolgus monkeys. AIDS Res. Hum. Retroviruses, 7, 271-277.

Pyle, S.W., Morein, B., Bess, J.W., Jr., Åkerblom, L., Nara, P.L., Nigida, S.M., Jr., Lerche, N.W., Robey, W.G., Fischinger, P.J. \& Arthur, L.O. (1989), Immune response to immunostimulatory complexes (iscoms) prepared from human immunodeficiency virus type 1 (HIV-1) or the HIV-1 external envelope glycoprotein (gp120). Vaccine, 7, 465-473.
Scott, M.T., Goss-Sampson, M. \& Bomford, R. (1985), Adjuvant activity of saponin: antigen localization studies. Int. Arch. Allergy, 77, 409-412.

Sjölander, A., Lövgren, K., Stahl, S., Aslund, L., Hanrsson, M., Nygren, P.A., Larsson, M., Hagstedt, M., Wahlin, B., Berzins, K., Uhlen, M., Morein, B. \& Perlmann, P. (1991), High antibody responses in rabbits immunized with influenza virus iscoms containing a repeated sequences of the Plasmodium falciparum antigen Pf155/RESA. Vaccine, 9, 443-450.

Speijers, G.J.A., Danse, L.H.J.C., Beuvery, E.C., Strik, J.J.T.W.A. \& Vos, J.G. (1987), Local reactions of the saponin Quil A and a Quil-A-containing iscom measles vaccine after intramuscular injection of rats : a comparison with the effect of DPT-polio vaccine. Fund. Appl. Toxicol., 10, 425-430.

Sundquist, B., Lövgren, K. \& Morein, B. (1988), Influenza virus iscoms: antibody response in animals. Vaccine, 6, 49-52.

Takahashi, H., Takeshita, T., Morein, B., Putney, S., Germain, R.N. \& Berzofsky, J.A. (1990), Induction of $\mathrm{CD}^{+}$cytotoxic $\mathrm{T}$ cells by immunization with purified HIV-1 envelope protein in iscoms. Nature (Lond.), 344, 873-875.

Thapar, M.A., Parr, E.J., Bozzola, J.J. \& Parr, M.B. (1991), Secretory immune responses in the mouse vagina after parenteral or intravaginal immunization with an immunostimulating complex (ISCOM). $\mathrm{Vac}$ cine, 9, 129-133.

Trudel, M., Nandon, F., Séguin, C., Boulay, G. \& Lussier, G. (1987), Vaccination of rabbits with a bovine herpesvirus type 1 subunit vaccine: adjuvant effect of iscoms. Vaccine, 5, 239-243.

Trudel, M., Boulay, G., Séguin, C., Nadon, F. \& Lussier, G. (1988a), Control of infectious bovine rhinotracheitis in calves with a BHV-1 subunit-ISCOM vaccine. Vaccine, 5, 525-529.

Trudel, M., Nadon, F., Séguin, C. \& Payment, P. (1988b), Neutralizing response of rabbits to an experimental rubella subunit vaccine made from immunostimulating complexes. Canad. J. Microbiol., 34, 1351-1354.

Trudel, M., Nadon, F., Séguin, C., Brault, S., Lusignan, Y. \& Lemieux, S. (1992), Initiation of cytotoxic T-cell response and protection of $\mathrm{BALB} / \mathrm{c}$ mice by vaccination with an experimental iscoms respiratory syncytial virus subunit vaccine. Vaccine, 10, 107-127.

Tsuda, T., Sugimura, T. \& Murakami, Y. (1991), Evaluation of glycoprotein gII iscoms subunit vaccine for pseudorabies in pig. Vaccine, 9, 648-652.

Ulaeto, D., Wallace, L., Morgan, A., Morein, B. \& Rickinson, A.B. (1988), In vitro T-cell responses to a candidate Epstein-Barr virus vaccine: human $\mathrm{CD4}^{+}$ $T$-cell clones specific for the major envelope glycoprotein gp340. Europ. J. Immunol., 18, 1689-1697.

Varsanyi, T.M., Morein, B., Löve, A. \& Norrby, E. (1987), Protection against lethal measles virus infection in mice by immune-stimulating complexes containing the hemagglutinin or fusion protein. J. Virol., 61, 3896-3901.

Visser, I.K.G., Van de Bildt, M.W.G., Brugge, H.N., Reijnders, P.J.H., Vedder, E.J., Kuiper, J., De Vries, P., Groen, J., Walvoort, H.C., UytdeHaag, F.G.C.M. \& Osterhaus, A.D.M.E. (1989), Vaccination of harbour seals (Phoca vitulina) against phocid 
distemper with two different inactivated canine distemper virus (CDV) vaccines. Vaccine, 7, 521-526.

Wahren, B., Nordlund, S., Akesson, A., Sundqvist, V.A. \& Morein, B. (1987), Monocyte and iscom enhancement of cell-mediated response to cytomegalovirus. Med. Microbiol. Immunol., 176, 13-19.

Weiss, H.P., Stitz, I. \& Becht, H. (1990), Immunogenic properties of iscom prepared with influenza virus nucleoprotein. Arch. Virol., 114, 109-120.

Watson, D.L., Lövgren, K., Watson, N.A., Fossum, C., Morein, B. \& Höglund, S. (1989), The inflammatory response and antigen localization following immunization with influenza virus iscoms. Inflammation, 13, 641-649.

Winter, A.J., Rowe, G.E., Duncan, J.R., Eis, M.J., Widsom, J., Ganem, B. \& Morein, B. (1988), Effectiveness of natural and synthetic complexes of porin and O polysaccaride as vaccines against Brucella abortus in mice. Infect. Immun., 56, 2808-2817.

Yewdell, J.W. \& Bennink, J.R. (1990), The binary logic of antigen processing and presentation to $T$ cells. Cell, 62, 203-206.

\title{
Liposomes as antigen carriers and adjuvants in vivo
}

\author{
A.M.J. Buiting (1), N. van Rooijen (1) and E. Claassen (2) \\ (I) Dept. Celbiology, Med. Fac., Vrije Universiteit, POB 7161, 1007-MC, Amsterdam and \\ ${ }^{(2)}$ Dept. Immunology and Med. Microbiology, Rijswijk (The Netherlands)
}

\section{Introduction}

Liposomes are artificially prepared spheres composed of concentric phospholipid bilayers, separated by aqueous compartments. Hydrophobic interactions of the phospholipids are the driving force of formation of liposomes when phospholipids are confronted with water. Liposomes may differ in their dimension, composition (different phospholipid and cholesterol content), charge (resulting from the charges of the component phospholipids), and structure (multi- $v s$ unilamellar). These physical properties and the location of antigens in liposomes determine the adjuvanticity of the liposome.

There are a number of important advantages of liposomes when used as immunoadjuvant: they are biodegradable, nontoxic, immunologically inert, simple to prepare and their composition can be varied to obtain the most efficient antigen-liposome preparation. In combination with other immunoadjuvants, liposomes may induce an extremely strong immune response.

The toxicity of certain antigens can be reduced by their incorporation into liposomes, and liposomes can be used to modulate the immune response (reviewed by Van Rooijen, 1990a). Liposomes have the ability to elicit both a cellular mediated immune response (CMI ; Garcon and Six, 1991) and a hu- moral immune response (HI) to antigens administered by a variety of routes, and there is a potential for selective interaction with populations of immunocompetent cells (Gregoriadis, 1990). In some cases, liposomes can be stronger adjuvants than complete Freund's adjuvant (CFA; Gregoriadis and Manesis, 1980; Brynestad et al., 1990), but when the antigens are e.g. immunogenic proteins, the immune response is slightly higher when CFA is used as adjuvant (Sanchez et al., 1980; Alving et al., 1986). Inclusion of cholesterol or sphingomyelin in liposomes increases the stability of their phospholipid bilayers and decreases their susceptibility to destruction by various serum components (Scherphof et al., 1978; Kirby et al., 1980; Claassen et al., 1988). Cholesterol inclusion also influences the interaction of liposomes with lymphoid and non-lymphoid cells involved in immune reactions (Van Rooijen and Van Nieuwmegen, 1982).

\section{Immune reaction against liposome-associated antigens and haptens}

The use of liposomes as immunoadjuvants was first described by Allison and Gregoriadis (1974). Since than, many studies have confirmed this capability to enhance the immune response to various antigens (Van Rooijen, 1988). Interest centred on the 